\title{
Gravidez e resposta sexual
}

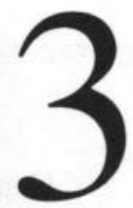

Paulo Roberto Bastos Canella*

Fabiane Muniz da Silva**

\section{RESUMO}

Objetivo: verificar a sexualidade do "casal grávido", tendo como parâmetros o desejo, a excitação e o orgasmo.

Metodologia: A amostra foi composta por um grupo de 81 mulheres e 78 homens totalizando, assim, 159 pessoas. A população foi do Estado do Rio de Janeiro. $O$ procedimento foi predominantemente quantitativo, porém, também foi qualitativo, porque quantificamos questões que investigavam qualidade. A pesquisa de campo teve como instrumento um questionário.

Resultados: Houve aumento discreto na intensidade desses parâmetros no homem diante da mulher grávida, enquanto na mulher ocorria uma redução mais marcante na atividade sexual. A avaliação do orgasmo, revelou uma dificuldade de seu reconhecimento por homens e mulheres durante a gestação.

* Professor titular do Instituto de Ginecologia da Universidade Federal do Rio de Janeiro (UFRJ) e do Mestrado em Sexologia da Universidade Gama Filho (UGF) do Rio de Janeiro, RJ.

** Mestre em Sexologia pela Universidade Gama Filho (UGF), Rio de Janeiro, RJ.

Recebido em 12.01.00

Aprovado em 22.01.00 
Conclusão: Podemos concluir que as modificações relativas aos principais parâmetros do ciclo de respostas sexuais se revelam pela maior redução do desejo, da excitação e do orgasmo na gestante, enquanto no homem as alterações são mínimas. É fase na qual pode desajustar ou reforçar as relações conjugais.

Palavras-chave: Sexualidade. Gravidez. Casal grávido. Resposta sexual. Desejo. Excitação. Orgasmo.

\section{INTRODUÇÃO}

Uma das situações reprimidas ainda hoje é o sexo físico e coital durante a gestação, talvez pela dissociação entre maternidade e sexo.

A expressão "casal grávido", é um fenômeno que vem sendo cunhado, nos meios nacionais e internacionais e que denota, em primeiro lugar, a prescrição de uma intensa participação e envolvimento masculino no decorrer da gestação. E a gravidez, assim como o parto e o puerpério, são situações vivenciadas pela mulher, mas envolve de forma igualmente comprometedora a vida do homem. (Salém, 1989)

Entre os mamíferos inferiores a cópula depende de um momento, o cio (ovulação). Já quando está grávida a fêmea repele o macho.

$\mathrm{Na}$ espécie humana, embora a atividade hormonal seja fundamental à reprodução, o contato sexual e a cópula é precedida, normalmente, das fases de desejo e excitação que são regidas por mecanismos fisiológicos, culturais, emocionais e psíquicos, que também são regidos pela córtex cerebral e pelo sistema límbico. Então, no humano, o comportamento sexual não é só determinado por hormônios, e grávida a mulher pode exibir aptidão para a cópula embora assinale-se modificações quando comparada a sua atividade sexual anterior a gestação em grande número de gestantes.

Segundo Lopes (1995), "sabendo-se que o ser humano é o único entre os animais que mantém uma atividade coital durante o período da gravidez, é de suma importância a discussão e pesquisa sobre o assunto". (p. 129)

Fazendo uma revisão em alguns tratados e manuais clássicos de obstetrícia, percebemos como é tão pouco tratado esse tema.

Briquet (1945), usando como argumento o fato de que a primigesta é mais sujeita a abortar por motivos de excitação, recomenda a abstenção nos três primeiros meses e permite o congresso sexual até o fim, do oitavo mês.

De Lee (1950), restringe as relações sexuais durante a gravidez, assim como Grelle (1960), Pérez (1942), principalmente ao risco grave de infecção e/ou abortos. Segundo Pérez, para vários autores como por exemplo Döderlein, Krönig entre outros, estas irrigações destroem as defesas naturais da vagina modificando a sua flora e assim o seu poder autoprotetor contra os germes patógenos. 
Javert (apud Resende, 1963) acreditava que o problema era o ato sexual com orgasmo, pois este poderia deflagrar contrações uterinas. Dizia que as mulheres que abortavam com facilidade, eram raramente frígidas ou que teriam orgasmo durante o sono.

Perkins (apud Lopes, 1995), em contradição a teoria de Javert, citado anteriormente, sugeriu que as pacientes anorgásmicas, teriam uma maior incidência de parto prematuro em relação às orgásmicas, devido ao maior sofrimento emocional que elas vivenciavam.

Clayen et al. (apud Lopes, op. cit.), mostraram que em três mulheres de idades gestacionais diferentes ocorreram nascimentos de crianças normais, mesmo com a observação de um aumento na atividade uterina e na freqüência cardíaca fetal imediatamente após o orgasmo.

Consideramos relevante no trabalho a busca de um maior conhecimento sobre resposta sexual durante a gravidez, podendo assim promover uma atuação clínica especializada, criando mecanismos terapêuticos que possam proporcionar uma resposta sexual mais satisfatória.

Um dos principais estudos sobre a resposta sexual da mulher grávida foi realizada por Masters e Johnson (1976).

Masters e Jonhson pesquisaram 111 mulheres entre 21 e 43 anos investigando a atividade sexual afetada pela gravidez. $\mathrm{O}$ interesse sexual teve grande variação no primeiro trimestre da gravidez, indo desde a rejeição voluntária de todas as formas físicas de atividade sexual até o aumento do interesse e da prática sexual, no segundo trimestre. Chamou a atenção um elevado grau de atividade sexual marcada pelo interesse, pela imaginação e por sonhos de atos sexuais. A necessidade de coito eficaz foi exigência significativa desta época da gravidez. Curioso é que 4 entre 19 mulheres estudadas nunca haviam apresentado interesse sexual em sua vida.

A masturbação passou a ser uma prática usual nas que não tinham parceiro, muitas vezes com aumento da freqüência quando comparada ao $1^{\circ}$ trimestre e a época anterior a gravidez. Os autores também observaram um aumento da conduta sexual objetiva e da realização multi-orgásmica do coito. Os sonhos eróticos foram mais numerosos e freqüentes.

No terceiro trimestre, as mulheres grávidas pela primeira vez tiveram forte redução na freqüência do coito, porém entre elas, muitas tiveram recomendação médica de abster-se de relações sexuais. Nas mulheres que já haviam tido filhos, a reação foi semelhante, porém menor do que nas primíparas. No $3^{\circ}$ trimestre, há uma acentuada queda na frequêencia da atividade sexual genitalizada. Muitas mulheres declararam que aceitavam o coito neste período para satisfazerem seus maridos.

Na prática, os autores relatam uma redução de 40 a $60 \%$ na atividade sexual dos casais durante a gravidez. Os possíveis fatores que contribuem para a redução do coito no $1^{\circ}$ trimestre seriam: medo de perder a gestação, rejeição à gravidez e/ou ao parceiro, problemas físicos (náuseas, vômitos, asia, cefaléia, etc.), aconselhamento médico, proibição religiosa. No $2 \circ$ trimestre o aumento do desejo seria explicado pela reafirmação da feminilida- 
de, segurança de consolidação da gravidez com desaparecimento do medo de abortar. Já a redução no 3 ำ trimestre correria por conta da modificação corporal com eventual queda da auto estima por não identificar sua imagem corporal com a sexualidade, da queda de interesse do parceiro posto que é comum a dissociação entre sexo e maternidade, ansiedade e medo do parto e aconselhamento de restrição pelo médico.

\section{MATERIAL E MÉTODOS}

O tipo de pesquisa utilizado foi o de sondagem descritiva, que tem como meta fazer emergir um fato, visando estender o campo de estudos e sugerir tendências a respeito de algo. A verificação foi realizada através de pesquisa de campo.

\section{Material (Instrumentos)} tionário.

A busca de informações se fez pela aplicação sistemática de um ques-

Sua finalidade foi comparar as diferenças entre sexo durante a gravidez e fora da gravidez, entre homens e mulheres. Usamos os parâmetros básicos - desejo, excitação e orgasmo - de Kaplan (1974).

\section{Amostra}

A população, ou universo pesquisado foi composto por indivíduos de cidades do Estado do Rio de Janeiro, onde a amostra foi selecionada aleatoriamente e dividida em dois grupos. Um grupo com 81 mulheres que haviam tido filho em no máximo 1 ano, ou que estivessem grávidas; e outro grupo com 78 homens cujas esposas houvessem tido filho, também, em no máximo 1 ano, ou que estivessem grávidas, totalizando, assim, 159 pessoas.

\section{Procedimento}

A aplicações foram individuais.

A princípio, o questionário foi aplicado em um posto de saúde no município de Niterói. Apesar de ser uma instituição pública, encontramos pessoas de vários níveis sociais, o que evitou que nossa pesquisa se limitasse a determinadas classes sociais.

Devido a algumas dificuldades, a pesquisa se estendeu a clínicas particulares e a outras cidades.

Selecionamos para atender os objetivos deste trabalho apenas as perguntas concernentes a desejo, excitação e orgasmo. Embora o questionário tenha sido bem mais amplo, constando 78 perguntas com a intenção de realizar uma ampla verificação das relações entre gravidez e exercício genital da sexualidade tanto pelo ponto de vista masculino quanto pelo feminino. 


\section{RESULTADOS}

Examinaremos os resultados encontrados nas respostas dadas pelo casal no que se refere ao objeto desse trabalho, qual sejam, as modificações nos parâmetros do ciclo de respostas sexuais segundo modelo Kaplan (1974).

A comparação entre as respostas dadas as perguntas: "Antes da gravidez, você tinha desejo sexual?" e "Durante a gravidez, você tinha desejo sexual?", mostrou:

\section{Figura 1}

Antes da gravidez você tinha desejo sexual?

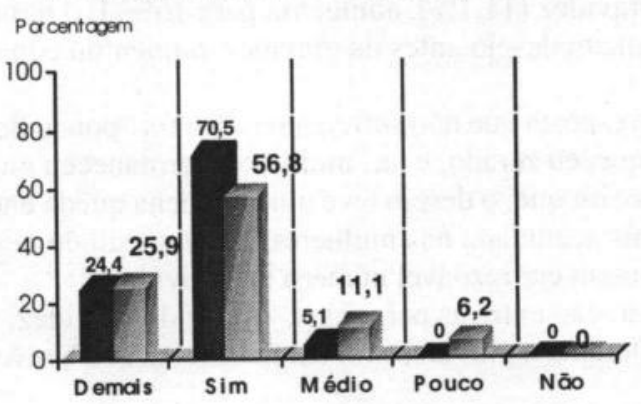

\section{a Homens Mulheres}

\section{Figura 2}

E durante a gravidez você tinha desejo sexual?

Pacoentogem

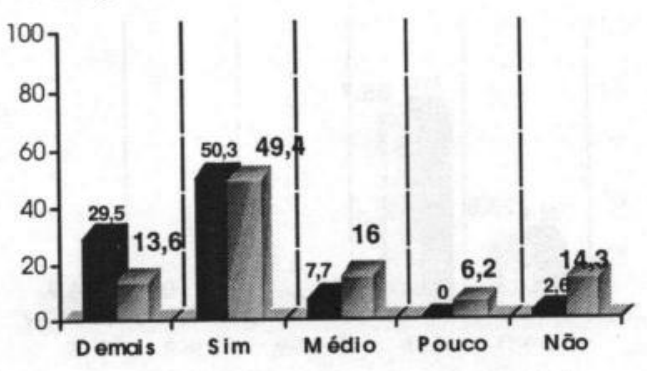

nomens Mulheres 
O percentual (24.4\%) dos homens que tinham acentuado desejo antes da gravidez, permaneceu praticamente o mesmo durante a gravidez; o aumento, pouco significativo, foi para $29.5 \%$. A porcentagem das mulheres que tinham acentuado desejo antes da gravidez (25.9\%), caiu praticamente a metade, indo para $13.6 \%$.

O desejo sexual dos homens caiu significativamente, de $70.5 \%$ de antes da gravidez para $50.3 \%$ durante a gravidez. No caso das mulheres em relação a essa mesma resposta, o desejo também caiu, porém muito menos, indo de $56.8 \%$ para $49.4 \%$.

Os homens, que tinham um desejo "médio" antes da gravidez (5.1\%), tiveram esse desejo aumentado para $7.7 \%$ durante a gravidez, aumento desprezível. Nenhum homem respondeu que não tinha desejo sexual, porém na gravidez de sua mulher, $2.5 \%$ dos homens passaram a não ter desejo, também desprezível. A porcentagem das mulheres que tinham um desejo médio antes da gravidez $(11.1 \%)$, aumentou para $16 \%$. E o número de mulheres que não tinham desejo antes da gravidez, aumentou consideravelmente para $14.8 \%$.

A única resposta que não sofreu alteração foi "pouco desejo", que nos homens permaneceu zerado, e nas mulheres, permaneceu nos $6.2 \%$.

Vemos assim que, o desejo teve uma pequena queda entre os homens, queda esta mais acentuada nas mulheres. Mesmo caindo em ambos os sexos, ele se mantém em razoável número de indivíduos.

A comparação entre as perguntas: "Antes da gravidez, você tinha excitação?" e "Durante a gravidez, você tinha excitação?", revelou:

\section{Figura 3}

Antes da gravidez você tinha excitação? Porcentagem

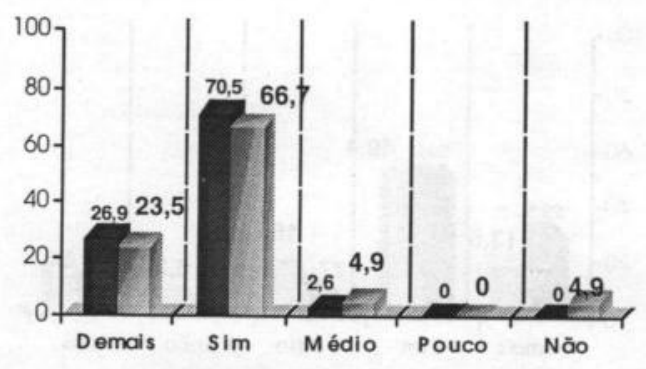

- Homens Mulheres 


\section{Figura 4}

E durante a gravidez você tinha excitação?

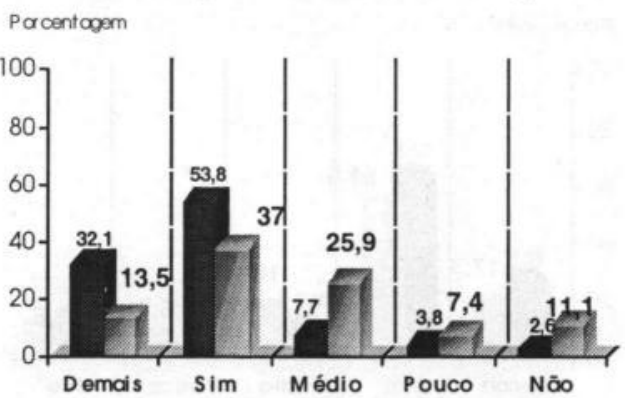

Womens Mulheres

Em relação à excitação antes da gravidez, os homens e as mulheres tiveram suas percentagens bastante igualadas, onde quase a totalidade das amostras dos dois grupos responderam que tinham excitação.

Já durante a gravidez, a excitação, teve nos homens uma queda de $11.5 \%$ ( 97.4 para $85.9 \%$ ); e nas mulheres uma queda mais significativa de $34.7 \%$ (de $90.2 \%$ para $55.5 \%$ ).

Comparando a diminuição de excitação durante a gravidez entre homens e mulheres, houve uma diferença três vezes maior para as mulheres.

Parece assim, que a excitação se reduz em ambos os parceiros, porém bem mais acentuadamente na mulher. Embora, neste trabalho, não figurem, os gráficos pertinentes a verificação quanto a fisiologia da resposta sexual, encontramos uma certa discrepância entre a excitação e a resposta sexual a ela (lubrificação e ereção), em especial nas respostas femininas. A lubrificação efetiva (demais e sim) caiu de $79 \%$ antes da gravidez para $51,8 \%$ durante a gravidez.

E por fim, a comparação entre as respostas dadas as perguntas: "Antes da gravidez, você tinha orgasmo?" e "Durante a gravidez, você tinha orgasmo?", demostrou: 


\section{Figura 5}

Antes da gravidez você tinha orgasmo?

Porcentogem

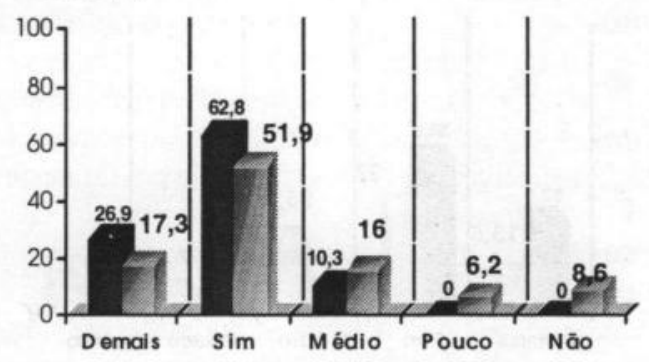

Eomens Mulheres

Figura 6

E durante a gravidez você tinha orgasmo?

Porcentogem

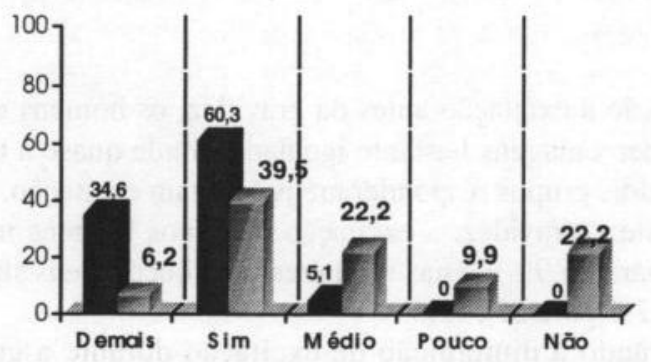

- Homens Mulheres

Antes da gravidez, $89.7 \%$ dos homens tinham orgasmo e somente $10.3 \%$ tinham orgasmo reduzido.

Nas mulheres o orgasmo estava presente em $69.2 \%$ e podemos inferir que $30.8 \%$ apresentaram alguma alteração, o que representa o triplo das respostas negativas masculinas.

Durante a gravidez, os homens curiosamente relataram um aumento no orgasmo, assim dos $10.3 \%$ dos homens que tinham orgasmo médio, 
$5.2 \%$ passaram a ter melhores orgasmos, só restando $5.1 \%$ com dificuldades orgásmicas.

O número de mulheres que tinham problemas orgásmicos, que já era grande, teve a percentagem aumentada durante a gravidez em $23.5 \%$. Das $69,2 \%$ que tinham orgasmo, $23.5 \%$, ou seja, $1 / 3$, passou a ter problemas, só restando um total de $45.7 \%$ de mulheres orgásmicas durante a gravidez.

As mulheres que, em comparação aos homens, já tinham uma diferença no ciclo de respostas sexuais, no momento da gravidez fica com uma diferença ainda maior, talvez, devido ao fato dela passar neste momento por mudanças muito significativas, como modificações do corpo, alterações emocionais e psicológicas ansiedade com o filho, com a evolução da gestação e com o parto.

De maneira geral, os homens, antes e durante a gravidez gostam mais de sexo, têm mais desejo sexual, mais prazer, mais excitação e mais orgasmo que as mulheres. $\mathrm{O}$ curioso que merece verificação mais profunda, é o aumento do número de homens relatando orgasmos com ótima e boa qualidade.

O orgasmo é uma exigência masculina que pouco sofre alteração no homem. Mas no geral, parece ser um problema feminino, e que se altera com a gestação.

De maneira geral, a relação sexual termina com o orgasmo do homem. Se ele é mais rápido que ela, o orgasmo não ocorrerá para a mulher. Se o homem continuasse estimulando a mulher, depois dele ter chegado ao orgasmo, talvez, teríamos uma freqüência diferente de orgasmo femininos.

\section{DISCUSSÃO}

Na realidade, o orgasmo feminino era valorizado na época em que se acreditava que ele era necessário à concepção. Assim que a ciência avançou e descobriu que mesmo sem o orgasmo a mulher concebia, este perdeu o valor. Passando assim, a ser questionável, pelo fato dele ser algo prazeroso, e sem necessidades procriativas.

Assim, o sexo passa ser algo que somente o homem tem direito ao prazer, pois este, além de precisar do orgasmo para liberar o sêmem, precisa da excitação para ter ereção e poder penetrar, enquanto que as respostas sexuais da mulher, só são necessárias para a qualidade da relação sexual, algo que, como vimos parecem desnecessárias à reprodução.

Segundo Andrade Silva (1996), com base no Cristianisno, sexo só seria tolerável por ser a única forma de preservação da espécie humana, assim sempre foi visto como algo culposo e pecaminoso e que deveria ser feito dentro de muitas regras como por exemplo: só era permitido nas épocas férteis, em locais e circunstâncias definidas, é claro dentro do casamento e com o objetivo de formar família. 
Assim a maternidade em nossa cultura, é percebida como algo divino. Mas esse milagre da vida passa a ser um dever para a mulher, o dever de gestar. E a gestação e o parto pode parecer um substituto do prazer sexual, sendo este visto como o "verdadeiro orgasmo" para a fêmea humana.

Já em uma observação feita por outro ângulo, ou seja, pela fisiologia, temos a idéia de que os hormônios são imprescindíveis para uma vida sexual satisfatória, pois este poderá garantir o desejo sexual, que sendo o primeiro do ciclo de respostas sexuais tende a ajudar nas fases seguintes, como por exemplo a excitação e o orgasmo. Mas parece que isto, em algumas vezes, fica só na teoria, principalmente na gestação, pois a queda dos androgênios pode tentar justificar a queda do desejo sexual de algumas mulheres. Contudo sabermos que esse acontecimento não é regra, pois analogicamente, temos informações (Canella e Nowak, 1997) que alguns autores relatam o aumento de desejo sexual em mulheres na fase folicular avançada.

Parece que em tudo isso ocorrem singularidades, pois podemos quase garantir a importância da relação desse casal, como um "tempero" essencial, que na maioria das vezes determina a qualidade e a satisfação da vida sexual dos grandes parceiros. A relação referida, não é padrão, pois cada casal, irá viver as características determinadas ao acaso. As pessoas, apesar de saberem as palavras chaves importantes para a vida, não conseguem sempre incluí-las em suas vidas de forma racional, pois a emoção deixa de acontecer naturalmente. Principalmente quando falamos de sentimentos nobres que queremos nos referir, como por exemplo o amor e a paixão.

A variação da atividade sexual depende de múltiplos fatores: educação, cultura, idade, tempo de atividade sexual, casamento, morar junto, número de parceiros, orientação sexual, condições de saúde, reprodução, momento da vida e também de hormônios - na prática foi até o momento impossível uma verificação científica da relação causal forte entre este último fator e atividade sexual.(Canella, 1999)

\section{CONCLUSÃO}

O desejo apresenta maior redução nas mulheres grávidas. A redução entre os homens também foi observada, porém sem maior significação; no homem o desejo pouco se altera com a gravidez da mulher.

De uma maneira geral $15 \%$ das mulheres declaram-se com pouco ou nenhum desejo, com a gravidez a ausência ou redução se acentua passando para $22,2 \%$.

A excitação cai mais na mulher o que acentua as eventuais incompatibilidades sexuais entre os casais.

O orgasmo masculino, pouco ou nada se altera diante da gestação da parceira, no entanto a grávida tem uma redução de $23.5 \%$. É outro fator a evidenciar desajustes sexuais pré-existentes. 
A sexualidade na gravidez modifica-se podendo reforçar o relacionamento ou ao contrário, contribuir para a dissolução dos vínculos. Tudo depende de fatores singulares.

\section{REFERÊNCIAS BIBLIOGRÁFICAS}

SALÉM, T. O casal igualitário: princípios e impasses. Revista Brasileira de Ciências Sociais, $\mathrm{n}^{\circ}$ 9, vol. 3, fev. 1989.

LOPES, G., GOODSON, L. e CAVALCANTI, S. Sexologia e ginecologia. Rio de Janeiro: Editora Médica e Científica L.T.D.A. - MEDSI, 1995.

BRIQUET J., R. Obstetrícia normal. São Paulo: Editora Renascença, 1945.

DE LEE, J. B. e GREENHILL, J. P. Tratado de obstetrícia. Rio de Janeiro: Editora Guanabara, 1950. Traduzido pelos Drs. A. Vespasiano Ramos e Ival Tavora Gama.

GRELLE, F. C. Manual de obstetrícia. Rio de Janeiro: Editora Atheneu, 1960.

PÉREZ, M. L. Tratado de obstetrícia. Vol. I. Rio de Janeiro: Editora Guanabara Waissman, Koogan L.T.D.A., 1942. Traduzida pelos Drs. Gessy Duarte Vieira e R. Marques de Cunha.

JAVERT, C. T. In: RESENDE, J. Obstetricia. Rio de Janeiro: Editora Guanabara Koogan, 1962.

PERKINS. In: LOPES, G., GOODSON, L. e CAVALCANTI, S. Sexologia e ginecologia. Rio de Janeiro: Editora Médica e Científica L.T.D.A. - MEDSI, 1995.

CLAYEN, P. et al. In: LOPES, G., GOODSON, L. e CAVALCANTI, S. Sexologia e ginecologia. Rio de Janeiro: Editora Médica e Científica L.T.D.A. - MEDSI, 1995.

MASTERS, W. H. e JOHNSON, V. E. A conduta sexual humana. Rio de Janeiro: Civilização Brasileira, 1976. Tradução de Dr. Duarte Costa.

KAPLAN, H. S. A nova terapia do sexo. Rio de Janeiro: Nova Fronteira, 1974. Tradução de Oswaldo Barreto e Silva.

ANDRADE SILVA, M. C. Psicologia da reprodução. In CANELLA, P. \& VITIELLO, N. Tratado de reprodução humana. (p. 148-1996). Rio de Janeiro: Cultura Médica, 1996.

CANELLA, P. R. B. e NOWAK, L. D. Aspectos Médicos da Sexualidade, p. 90171. In Sexologia - Fundamentos para uma Visão Interdissiplinar. Org. SILVA, M. C. A. e col. Rio de Janeiro, Editoria central da U.G.F., 1997.

CANELLA, P. R. B. Efeitos dos vários hormônios de reposição na sexualidade. Femina 29(9):727-732, 1999. 